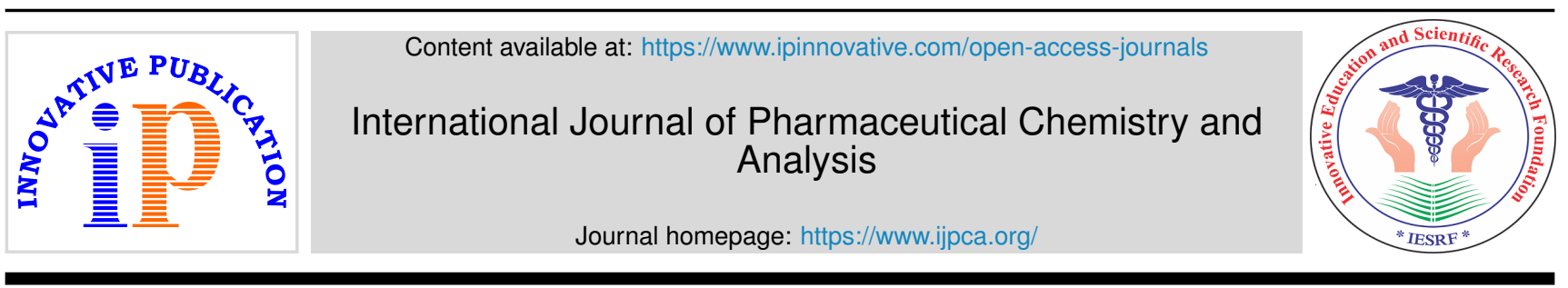

\title{
Editorial
}

\section{Repurposed application of doxycycline in COVID 19 treatment}

\author{
Deepak Kumar Dash ${ }^{1}$, Neelesh Chaubey ${ }^{2}$, Anil Kumar Sahu ${ }^{1}$, Vaibhav Tripathi ${ }^{1}{ }^{*}$, \\ Lalit Pal ${ }^{1}$ \\ ${ }^{1}$ Royal College of Pharmacy, Raipur, Chhattisgarh, India \\ ${ }^{2}$ Sri Satya Sai University of Technology \& Medical Sciences, Sehore, Madhya Pradesh, India
}

\section{A R T I C L E I N F O}

Article history:

Received 10-12-2020

Accepted 12-12-2020

Available online 13-01-2021 (c) This is an open access article distributed under the terms of the Creative Commons Attribution License (https://creativecommons.org/licenses/by/4.0/) which permits unrestricted use, distribution, and reproduction in any medium, provided the original author and source are credited.
Corona viruses are a large family of viruses which may cause illness in animals or humans. In humans, several coronaviruses are known to cause respiratory infections ranging from the common cold to more severe diseases such as Middle East Respiratory Syndrome (MERS) and Severe Acute Respiratory Syndrome (SARS). ${ }^{1,2}$ Most recently discovered coronavirus causes COVID-19 is the infectious disease caused by the most recently discovered corona virus. This new virus and disease were unknown before the outbreak began in Wuhan, China, in December 2019. ${ }^{3}$

The most common symptoms of COVID-19 are fever, tiredness, and dry cough. ${ }^{4}$ Some patients may have aches and pains, nasal congestion, runny nose, sore throat or diarrhea. ${ }^{5}$ These symptoms are usually mild and begin gradually. Although some people become infected with the virus but they do not develop any symptoms. Most people (about 80\%) recover from the disease without needing special treatment. Around 1 out of every 6 people who gets COVID-19 becomes seriously ill and develops difficulty breathing. ${ }^{6}$ Older people, and those with underlying medical problems like high blood pressure, heart problems or diabetes, are more likely to develop serious illness. ${ }^{7}$ People with fever, cough and difficulty breathing should seek medical attention.

\footnotetext{
* Corresponding author.

E-mail address: vaibhu.07@gmail.com (V. Tripathi).
}

People can catch COVID-19 from others who have the virus. The disease can spread from person to person through small droplets from the nose or mouth which are spread when a person with COVID-19 coughs or exhales. ${ }^{8}$ These droplets land on objects and surfaces around the person. Other people then catch COVID-19 by touching these objects or surfaces, then touching their eyes, nose or mouth. People can also catch COVID-19 if they breathe in droplets from a person with COVID-19 who coughs out or exhales droplets. ${ }^{9}$ This is why it is important to stay more than 1 meter ( 3 feet) away from a person who is sick.

The risk of catching COVID-19 from the feces of an infected person appears to be low. While initial investigations suggest the virus may be present in feces in some cases, spread through this route is not a main feature of the outbreak. ${ }^{10,11}$

It is not certain how long the virus that causes COVID-19 survives on surfaces, but it seems to behave like other corona viruses. ${ }^{12}$ Studies suggest that corona viruses (including preliminary information on the COVID-19 virus) may persist on surfaces for a few hours or up to several days. This may vary under different conditions (e.g. type of surface, temperature or humidity of the environment). ${ }^{13}$

The chances of being infected or spreading COVID19 can be reduced by taking some simple precautions:

However there is no significant drug is can be used as hundred $100 \%$ cure for this disease. There are some 
Regularly and thoroughly clean hands with an alcohol based hand rub or wash them with soap and water.

Avoid touching eyes, nose and mouth. Hands touch many surfaces and can pick up viruses.

Make sure that the people around us, follow good respiratory hygiene. This means covering mouth and nose with bent elbow while coughing or sneezing.

Keep up to date on the latest COVD-19

hotspots (cities or local areas where COVID-19 is spreading widely).

Stay home in case of feeling unwell.

Follow the guidelines which are outlined by the government authorities.

Fig. 1: List of precautionary measures ${ }^{14,15}$ 
antibiotics and vitamins which are used in lowering down the effect of corona virus. ${ }^{16}$

Though azithromycin is an antibiotic and thus ineffective alone against viruses, some clinicians have seen limited success in COVID-19 coronavirus diseased patients when adding it to chloroquine and/or hydroxy-choloroquine in the sickest patients. ${ }^{17,18}$

\section{Antiviral effects of doxycycline}

Hydroxychloroquine with doxycycline seem to be a better alternative to azithromycin for the treatment of corona infection especially in geriatric patients. ${ }^{19}$ Doxycycline and other tetracycline derivatives such as minocycline exhibit anti-inflammatory effects along with in vitro antiviral activity against several RNA viruses. ${ }^{20}$ Use of these agents has been associated with clinical improvement, even reversal of cytokine storm in some infections caused by RNA viruses, such as dengue fever. ${ }^{21}$

The mechanism of the antiviral effects of tetracycline derivatives may be secondary to transcriptional up regulation of intracellular zinc finger antiviral protein (ZAP), an encoding gene in host cells. ZAP can also bind to specific target viral mRNAs and represses the RNAs translation. ${ }^{22,23}$

Doxycycline can repress Dengue virus infection in Vero cells through the inhibition of dengue serine protease enzymes and of viral entry. Doxycycline showed the capacity to inhibit dengue virus replication in Vero cells culture and likely it interacts with the dengue virus E protein that is required for virus entry. ${ }^{24,25}$

Similarly, doxycycline controls Chikungunya virus (CHIKV) infection through the inhibition of CHIKV cysteine protease of Vero cells and showed significant reduction of CHIKV blood titer of mice. ${ }^{26}$

In addition, doxycycline is highly lipophilic antimicrobials that chelate zinc compounds on matrix metalloproteinases (MMPs) of mammalian cells, and an in vitro study showed that murine coronaviruses rely on MMPs for cell fusion and viral replication. ${ }^{22}$ Different components of viral combination and replication by corona viruses use host proteases could be a potential objective to doxycycline. As lung insusceptible injury/ARDS is conspicuous in serious COVID patients, restraining MMPs may help fix the harmed lung tissue and upgrade recuperation.

\section{Anti-inflammatory effects of doxycycline}

In COVID-19, elevated levels of blood interleukin (IL)6 have been more commonly observed in severe COVID19 illness and among non-survivors, ${ }^{27}$ suggesting that mortality might be due to virally-driven hyper inflammation and to cytokine storm. Intense pro-inflammatory state has a central role in the pathogenesis of COVID 19, leading to cytokine storm. ${ }^{28}$
Importantly, doxycycline reduced pro-inflammatory cytokines, including IL-6 and tumor necrosis factor (TNF)$\alpha$, in patients with dengue hemorrhagic fever, and the mortality rate was $46 \%$ lower in the doxycycline-treated group $(11.2 \%)$ than in the untreated group $(20.9 \%){ }^{29}$

In addition, severe acute respiratory syndrome-related coronavirus (SARS-CoV) encompasses a papain-like protease that significantly triggers an early growth response protein 1 (Egr-1)-dependent activation of transforming growth factor beta 1 (TGF- $\beta 1$ ), resulting in up-regulation of pro-fibrotic responses in vitro and in vivo in the lungs. [30-31] Recent computational methods study identified doxycycline among the drugs that could potentially be used to inhibit SARS-CoV-2 papain-like protease. ${ }^{30,31}$

\section{Conclusion}

Doxycycline is an expanded spectrum antibiotic that has additionally documented antiviral and anti-inflammatory properties. As doxycycline is reasonable and generally accessible, has a safe therapeutic index profile, and is an alluring alternative for the treatment of COVID-19 as well as potentially alleviating the lung sequelae. In spite of the fact that there is no contention on the multiple utilization of doxycycline; outrageous consideration is suggested while repurposing the medication for COVID-19 treatment. 'Battling a sickness with previously existing anti-infection agents' and 'antimicrobial obstruction progression' resemble two arms of an equilibrium that must be deliberately equilibrated. Any unevenness by the unseemly or unpredictable application of the repurposed medication would cause an appalling increase in AMR (anti- microbial resistance).

Because of the COVID-19 pandemic and lack of medications, numerous nations have begun their own mass generic medication manufacturing units which are probably going to modify the drug production scene expanding the likelihood of more ecological defilement and drug abuse. Aside from its therapeutic application, doxycycline is also utilized in veterinary medication and farming. It is quite possibly the most richly utilized antibiotics around the world and the general wellbeing crisis presented by the COVID-19 pandemic has influenced its utilization. These hitches must be cautiously and carefully observed to contain the developing AMR which is unarguably an inconspicuous pandemic that would endure beyond the corona virus pandemic.

\section{Source of Funding}

None.

\section{Conflicts of Interest}

The authors declare that there is no conflict of interest. 


\section{References}

1. Naresh BV. A review of the 2019 novel coronavirus (covid-19) pandemic. Asian J Pharm Res. 2020;10(3):233-8. 101:10.5958/223]56012020.000404.

2. Yin Y, Wunderink RG. MERS, SARS and other coronaviruses as causes of pneumonia. Respirol. 2018;23(2):130-7. do1:10.1111/resp.13196.

3. Daga MK, Kumar N, Aarthi J, Mawari G, Garg S, Rohatgi I. From SARS-CoV to Coronavirus Disease 2019 (COVID-19)-A Brief Review. J Adv Res Med. 2019;6(4):1-9.

4. Meyers MH. A case of COVID-19 infection: Chief symptom, diarrhea. Am Fam Physician. 2020;101:580.

5. Toptan T, Aktan Ç, Başarı A, Bolay H. Case Series of Headache Characteristics in COVID-19: Headache Can Be an Isolated Symptom.

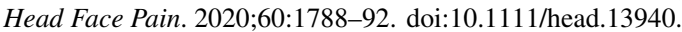

6. World Health Organization. Preparedness, prevention and control of COVID-19 in prisons and other places of detention: Interim guidance 15 March 2020. World Health Organization. Regional Office for Europe; 2020.

7. Patel U, Malik P, Usman MS, Mehta D, Sharma A, Malik FA, et al. Age-Adjusted Risk Factors Associated with Mortality and Mechanical Ventilation Utilization Amongst COVID-19 Hospitalizations-a Systematic Review and Meta-Analysis. 2020;p. 1-10. doi-10.1007/s42399-(1)20-(0)476-w.

8. Atangana E, Atangana A. Facemasks simple but powerful weapons to protect against COVID-19 spread: Can they have sides effects? Results Phys. 2020;19:103425. do1:10.1016/j.rinp.2020.103425

9. World Health Organization. Getting your workplace ready for COVID-19: How COVID-19 spreads, 19 March 2020. World Health Organization; 2020 .

10. Jones DL, Baluja MQ, Graham DW, Corbishley A, McDonald JE, Malham SK, et al. Shedding of SARS-CoV-2 in feces and urine and its potential role in person-to-person transmission and the environmentbased spread of COVID-19. Sci Total Environ. 2020;749:141364. do1:10.1016/].scitotenv.2020.141364,

11. Elsamadony M, Fujii M, Miura T, Watanabe T. Possible transmission of viruses from contaminated human feces and sewage: Implications for SARS-CoV-2. Sci Total Environ. 2021;755:142575. do1:10.1016/j.scitotenv.2020.142575,

12. Rahmani AR, Leili M, Azarian G, Poormohammadi A. Sampling and detection of corona viruses in air: A mini review. Sci Total Environ. 2020;740:140207. do1:10.1016/].scitotenv.2020.140207.

13. Marquès M, Domingo JL. Contamination of inert surfaces by SARSCoV-2: persistence, stability and infectivity. A review. Environ Res 2020; do1:10.1016/].envres.2020.110559

14. Almutairi AF, BaniMustafa A, Alessa YM, Almutairi SB, Almaleh Y. Public Trust and Compliance with the Precautionary Measures Against COVID-19 Employed by Authorities in Saudi Arabia</p $>$. Risk Manag Healthc Policy. 2020;13:753-60. do1:10.2147/rmhp.s257287.

15. Tong KK, Chen JH, Yu EW, Wu AM. Adherence to COVID19 Precautionary Measures: Applying the Health Belief Model and Generalised Social Beliefs to a Probability Community Sample. Applied Psychology. Health Well-Being. 2020;12(4):1205-23.

16. Lisi L, Lacal PM, Barbaccia ML, Graziani G. Approaching coronavirus disease 2019: Mechanisms of action of repurposed drugs with potential activity against SARS-CoV-2. Biochem Pharmacol. 2020;180:114169. d01:10.1016/].bcp.2020.114169.

17. Oldenburg CE, Doan T. Azithromycin for severe COVID-19. Lancet. 2020;396(10256):936-7.

18. Hache G, Rolain J, Gautret P, Deharo C, Brouqui P, Raoult D. Combination of hydroxychloroquine plus azithromycin as potential treatment for COVID 19 patients: pharmacology, safety profile, drug interactions and management of toxicity. Preprint. 2020;

19. Malek AE, Granwehr BP. Doxycycline as an Alternative to Azithromycin in Elderly Patients. Int $J$ Antimicrob Agents.
2021:57(1):106168. do1:10.1016/1.11antimicag.2020.106168

20. Naveja JJ, Madariaga-Mazón A, Flores-Murrieta F, Granados-Montiel $\mathrm{J}$, Maradiaga-Ceceña M, Alaniz VD, et al. Union is strength: antiviral and anti-inflammatory drugs for COVID-19. Drug discovery today. Drug Discov Today. 2020; do1:10.1016/].drudis.2020.10.018.

21. Arpornsuwan M, Arpornsuwan M. Early Diagnosis and Early Management Proposal in Dengue Infection: New Normal to Applied Strategy for COVID-19 Infection. SSRN Electron J. 2020:01:102139/ssrn.36494/2

22. Malek AE, Granwehr B, Kontoyiannis DP. Doxycycline as a Potential Partner of COVID-19 Therapies. IDCases. 2020;21:e00864. do1:10.1016/].1der.2020.e00864.

23. Zhu Y, Wang X, Goff SP, Gao G. Translational repression precedes and is required for ZAP-mediated mRNA decay. EMBO J. 2012;31:423646. 001:10.1038/emboj.2012.271.

24. Schor SJ. BIKE Regulates Dengue Virus Infection Via CLINT1 Phosphorylation and is a Host Target for Broad-spectrum Antivirals. Stanford University; 2020.

25. Rothan HA, Mohamed Z, Paydar MJ, Rahman NA, Yusof R. Inhibitory effect of doxycycline against dengue virus replication in vitro. Arch Virol. 2014;159:711-8. 101:10. T001/s00705-(13-1880-7.

26. Rothan HA, Bahrani H, Mohamed Z, Teoh TC, Shankar EM, Rahman NA, et al. A combination of doxycycline and ribavirin alleviated chikungunya infection. PloS one. 2015;10(5):126360.

27. Zeng Z, Yu H, Chen H, Qi W, Chen L, Chen G, et al. Longitudinal changes of inflammatory parameters and their correlation with disease severity and outcomes in patients with COVID-19 from Wuhan, China. Crit Care. 2020;24(1):1-2.

28. Fara A, Mitrev Z, Rosalia RA, Assas BM. Cytokine storm and COVID-19: a chronicle of pro-inflammatory cytokines. Open Biol. 2020;10:200160. 101:D.T098/rsob.200160.

29. Fredeking T, Zavala-Castro J, Gonzalez-Martinez P, MoguelRodríguez W, Sanchez E, Foster M. Dengue Patients Treated with Doxycycline Showed Lower Mortality Associated to a Reduction in IL-6 and TNF Levels. Recent Patents Anti-Infect Drug Discov.

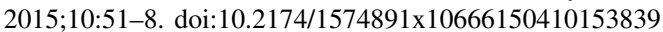

30. Maurya DK. A combination of ivermectin and doxycycline possibly blocks the viral entry and modulate the innate immune response in COVID-19 patients. ChemRxiv Preprint. 2020:01026434/chemrxiv. $2630539 . \mathrm{V}$.

31. Gul S, Ozcan O, Asar S, Okyar A, Barıs I, Kavakli IH. In silico identification of widely used and well-tolerated drugs as potential SARS-CoV-2 3C-like protease and viral RNA-dependent RNA polymerase inhibitors for direct use in clinical trials. J Biomol

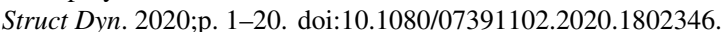

\section{Author biography}

\section{Deepak Kumar Dash, Principal}

Neelesh Chaubey, Principal

Anil Kumar Sahu, Assistant Professor

Vaibhav Tripathi, Assistant Professor

Lalit Pal, Student

Cite this article: Dash DK, Chaubey N, Sahu AK, Tripathi V, Pal L. Repurposed application of doxycycline in COVID 19 treatment. Int J Pharm Chem Anal 2020;7(4):151-154. 